\title{
Clinical characteristics and causes of visual impairment in a low vision clinic in northern Jordan
}

This article was published in the following Dove Press journal: Clinical Ophthalmology

\section{May M Bakkar \\ Eman A Alzghoul \\ Mera F Haddad}

Faculty of Applied Medical Sciences, Department of Allied Medical Sciences, Jordan University of Science and Technology, Irbid, Jordan
Correspondence: May M Bakkar Faculty of Applied Medical Sciences, Department of Allied Medical Sciences, Jordan University of Science and Technology, PO Box 3030, Irbid 22110, Jordan

Tel +96227201000

Fax+962 27201087

Email bakkar.may@gmail.com
Aim: The aim of the study was to identify causes of visual impairment among patients attending a low vision clinic in the north of Jordan and to study the relevant demographic characteristics of these patients.

Subjects and methods: The retrospective study was conducted through a review of clinical records of 135 patients who attended a low vision clinic in Irbid. Clinical characteristics of the patients were collected, including age, gender, primary cause of low vision, best corrected visual acuity, and current prescribed low vision aids. Descriptive statistics analysis using numbers and percentages were calculated to summarize categorical and nominal data.

Results: A total of 135 patients (61 [45.2\%] females and 74 [54.8\%] males) were recruited in the study. Mean age \pm standard deviation for the study population was $24.53 \pm 16.245$ years; age range was 5-90 years. Of the study population, 26 patients $(19.3 \%)$ had mild visual impairment, 61 patients $(45.2 \%)$ had moderate visual impairment, 27 patients $(20.0 \%)$ had severe visual impairment, and 21 patients (15.6\%) were blind. The leading causes of visual impairment across all age groups were albinism (31.9\%) and retinitis pigmentosa (RP) (18.5\%). Albinism also accounted for the leading cause of visual impairment among the pediatric age group ( $0-15$ years) while albinism, RP, and keratoconus were the primary causes of visual impairment for older patients. A total of 59 patients $(43.7 \%)$ were given low vision aids either for near or distance. The only prescribed low vision aids for distances were telescopes. For near, spectacle-type low vision aid was the most commonly prescribed low vision aids.

Conclusion: Low vision services in Jordan are still very limited. A national strategy programme to increase awareness of low vision services should be implemented, and health care policies should be enforced to cover low vision aids through the national medical insurance.

Keywords: low vision, visual impairment, low vision aids, Jordan, low vision services

\section{Introduction}

Visual impairment is considered a public health problem that has social and economic impact on societies in both developed and developing countries. It has been reported that visual impairment may affect a person's daily life activities by impacting on physical well-being, psychological state, and productivity. ${ }^{1-3}$ The term "visual impairment" collectively refers to low vision and blindness. Worldwide, visual impairment affects all communities alike; however, its prevalence is not distributed evenly throughout the world. According to the WHO reports, the global prevalence of visual impairment was reported in 2010 as around 285 million people, of whom around 39 million people were blind and around 246 million people had low vision. ${ }^{4}$

The prevalence of visual impairment for each country may vary with the causes of visual impairment. These causes could be due to genetic factors such as retinitis pigmentosa (RP) or other retinal degenerations, or acquired, for example, as a result of 
systemic disease, such as diabetic retinopathy due to diabetes mellitus. ${ }^{5}$ The prevalence and causes of visual impairment may also be different according to the affected age group. For example, different reports throughout the world have suggested that the leading causes of visual impairment in the pediatric age group of less than 15 years were genetic disorders such as albinism, congenital glaucoma, and congenital cataract. ${ }^{1,6-8}$ In contrast, age-related macular degeneration (AMD), acquired cataract, and diabetic retinopathy were reported as the main causes of visual impairment in older age groups. $^{9-13}$ It is estimated that $80 \%$ of all visual impairment can be either preventable or treatable., ${ }^{5,14}$

Low vision aids and rehabilitation therapy are considered the primary methods of intervention in visually impaired patients. The aim of low vision aids is to improve patient's performance in certain tasks through efficient use of residual vision through prescribing optical and non-optical electronic devices. ${ }^{15}$ The most commonly prescribed and enduring low vision aids are optical devices. These may include spectacletype low vision aids, stand magnifiers, handheld magnifiers, and telescopic systems. These optical devices aim to improve visual functions by enhancing perceived retinal images through magnification, image displacement, light filtering, or light condensation. ${ }^{15}$ The non-optical electronic devices generally include a number of adaptations in perceived image such as contrast, spatial frequency, and brightness range or edge boldness. ${ }^{16,17}$

Few population-based studies have reported the prevalence and causes of visual impairment and blindness in the Middle East. In a study conducted in Riyadh (KSA), the main reported cause of low vision in children was optic nerve atrophy (28.9\%). This was followed by RP, diabetic retinopathy, and macular degeneration in the older age group. ${ }^{28}$

In Taharan (Iran), two main studies have reported the distribution of visual impairment. In one study, the rate of severe visual impairment was reported at $8.9 \%$ in the pediatric age group with the most common cause of low vision being retinal disease, while optic nerve and optic tract diseases, vitreous and globe disorders, congenital cataract, and glaucoma were less common causes. In another study conducted in Iran, the prevalence of visual impairment was $41.8 \%$ among people aged 50 years, with the leading causes of visual impairment being diabetic retinopathy and agerelated macular degeneration. ${ }^{10}$

In Jordan, studies about causes of visual impairment are also lacking. In a study that generally examined the pattern of various causes of decreased visual acuity (VA) within 18- to 25-year-old healthy adults in Jordan, it was suggested that refractive errors and amblyopia were the major causes of reduced VA. ${ }^{18}$ In another report that identified causes of blindness among adults in a hospital-based study, cataract and diabetic retinopathy were the main causes of blindness. ${ }^{9}$ However, neither of the two studies specified the causes of visual impairment and low vision among the studied population.

According to the recently non-published data from the German-Jordanian University (GJU) in 2016, it has been estimated that there are three times more people with low vision than people with blindness in Jordan, including 6,901 children with low vision, of whom about 2,300 children are blind.

The aim of this retrospective study is to identify characteristics of patients with visual impairment and the main causes that led to visual impairment in a low-vision clinic located in the northern area of Jordan. As it becomes increasingly difficult to ignore the deep impacts of visual impairment among the population in the Middle East in general, and in Jordan in particular, there is an immense need to assess the situation of vision rehabilitation services and accessibility of patients to such services in Jordan. This could help us in the reformation of health-care policies and increasing levels of awareness of low vision services in Jordan in order to make the low vision aids more affordable for affected patients.

The data in this study can also provide a more detailed understanding of the situation of low vision services in Jordan in general and in the northern area of Jordan in particular.

\section{Subjects and methods}

This retrospective study was conducted through a review of the clinical records of 135 patients who attended a low vision clinic affiliated to Jordan University of Science and Technology (JUST) between January 2010 and December 2015.

Patients were referred to the low vision clinic from different Ministry of Health ophthalmology clinics in the northern area of Jordan that include the following cities: Irbid and Jordan valley, Ajloun, Al Mafraq, Jarash, and Al Ramtha. All patients were diagnosed for causes of visual impairment by ophthalmologists. During the study, the primary cause of visual impairment was recorded based on ophthalmologist diagnosis. Further examination was performed by optometrists at the low vision clinic to assess visual acuity, refraction, and visual demands.

Distance VA test was measured at $3 \mathrm{~m}$ by using Lea Symbols ${ }^{\circledR}$ which were designed to start measurements from $3 \mathrm{~m}$. Further VA testing was done when vision was found to be less than $3 / 60$. Near VA was also measured using Lea Symbols near vision chart at $40 \mathrm{~cm}$. 
VA was measured both with and without correction in patients who were wearing glasses and/or using near and far optical device aids. Contrast sensitivity was measured at different contrast levels (5\%, 2.5\% 1.25\%) using low contrast (semi-translucent) Lea symbols chart with illuminated cabinet.

Throughout the study, visual impairment classification followed the categories of the International Classification of Diseases Update and the Revision in 2010 (ICD-10). ${ }^{19}$ In this regard, visual impairment is classified into four levels: mild visual impairment (VA $6 \geq 18$ ), moderate visual impairment (VA 6/18 to 6/60), severe visual impairment (VA 6/60 to $3 / 60$ ), and blindness (VA $<3 / 60$ ). Both moderate visual impairment and severe visual impairment are grouped under the term of "low vision", which is defined as "patients who have a visual acuity less than $6 / 18$ in the better eye with best correction."

All patients received objective refraction using a Neitz streak retinoscope (RX-RC, Japan). This was followed by subjective refraction to record best corrected visual acuity (BCVA) for each eye. At the end of the examination, patients were then provided with suitable visual aids for distance or near depending on their visual demand. Each patient was asked to choose more than one visual aid (for both near and distance) depending on patient's visual requirement.

The collected data for the study included demographic characteristics of the patients (age, gender, and family history of ocular diseases). Patients were categorized according to their age into five age groups: from birth to 16 years, 17 to 33 years, 34 to 50 years, and older than 50 years. BCVA, primary cause of low vision or visual impairment, and currently prescribed low vision aids for near and distance were also recorded.

\section{Ethics approval}

The Institutional Review Board (IRB) committee at JUST formally approved the protocol of the study. The study complied with guidelines of the declaration of Helsinki. Patient informed consent was not required in our retrospective study by the IRB, and steps were taken to ensure the anonymity and confidentiality of the data.

\section{Data analysis}

Data were analyzed using the Statistical Package for Social Sciences (SPSS) software version 20 (SPSS ${ }^{\circledR}$ : Inc., Chicago, IL, USA). Descriptive statistics analysis using numbers and frequency (percentages) was done to summarize categorical and nominal data.

\section{Results}

Medical records of 135 patients (61 females, 74 males) were included in the study. The average age of the study group was $24.53 \pm 16.245$ years and ranged from 5 to 90 years. The majority of the study population $(80 \%)$ were under 33 years. Table 1 shows the basic demographic characteristics of the patients including gender, age group, and family history of ocular diseases.

Levels of visual impairment among patients were classified according to the WHO standards, which are based on patient's BCVA. A total of 26 patients (19.3\%) had mild visual impairment (VA $6 \geq 18), 61$ patients $(45.2 \%)$ had moderate visual impairment (VA 6/18 to 6/60), 27 patients (20.0\%) had severe visual impairment (VA 6/60 to 3/60), and 21 patients $(15.6 \%)$ were blind (VA $<3 / 60)$.

Causes of visual impairment in the study population are shown in Figure 1, and the most common two causes of visual impairment across all age groups in the study population were albinism with 43 (31.9\%) followed by RP with 25 (18.5\%) and juvenile macular degeneration (JMD) with 14 (10.3\%). Family history of ocular diseases was reported by $56.3 \%$ of the patients. Patients reported presence of family history of their ocular disease as the following: albinism, 29 (67\%); RP, 17 (68\%); and JMD, 6 (43\%).

Treatable causes of visual impairment in the study included congenital cataract, acquired cataract, keratoconus, glaucoma, retinopathy of prematurity (ROP), and strabismus. Of the study population, 72 patients $(53.3 \%)$ presented with nystagmus along with their primary cause of visual impairment.

Table 2 shows the frequency of primary causes of visual impairment among different age groups. The most common causes of visual impairment among the pediatric age group were albinism and congenital cataract. Albinism, RP, and keratoconus were the leading causes in the older age groups.

Table I Demographic characteristics (age, gender, and family history) of the study population

\begin{tabular}{ll}
\hline Characteristics & Total no (\%) \\
\hline Age (years) & \\
$0-16$ & $53(39.3)$ \\
$17-33$ & $55(40.7)$ \\
$34-50$ & $15(11.1)$ \\
$>50$ & $12(8.9)$ \\
Gender & \\
Female & $61(45.2)$ \\
Male & $74(54.8)$ \\
Family history of ocular diseases & \\
Yes & $76(56.3)$ \\
No & $59(43.7)$ \\
\hline
\end{tabular}




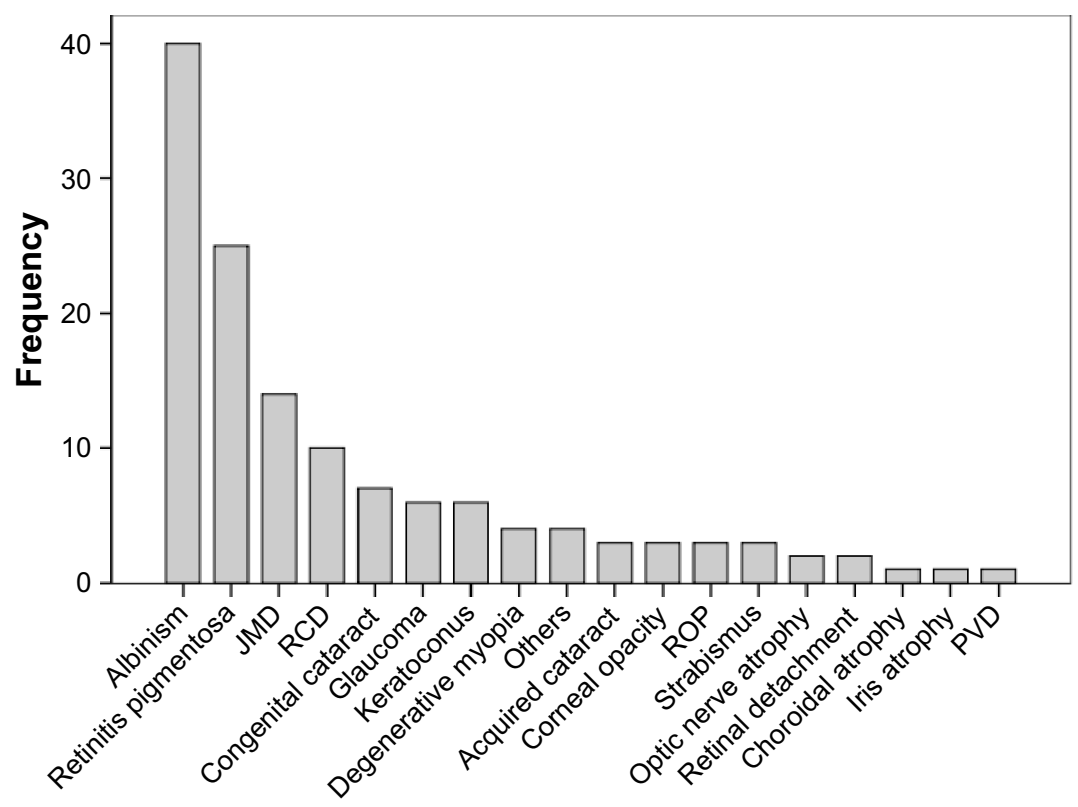

Figure I Causes of visual impairment in the study population.

Note: "Others" include Stargardt disease and Wolfram syndrome.

Abbreviations: JMD, juvenile macular degeneration; RCD, rod-cone dystrophy; ROP, retinopathy of prematurity; PVD, posterior vitreous detachment.

The data showed that, overall, only 59 patients (43.7\%) were given low vision aids either for near or distance as listed in Table 3. For distance, only 22 patients (16.3\%) received low vision aids with the only prescribed low vision aids being telescopes. For near need, 43 patients (31.9\%) received low vision aids, with the most frequently prescribed low vision appliances for near were spectacle-type low vision aids.

\section{Discussion}

Visual impairment is considered one of the major health problems around the world. ${ }^{1}$ Many reports from different countries about the prevalence and causes of visual impairment have shown variations in the causes of visual impairment. Unfortunately, data in the Middle East are lacking. Hence, this retrospective study looked to investigate causes of visual impairment in a clinical population who attended a low vision clinic in northern Jordan.

The study was conducted by carefully reviewing 135 medical records of patients who attended the only low vision clinic located in Irbid, the third largest city in Jordan.

The data showed that more male patients (54.4\%) were referred to the clinic than female patients. Similar findings were extensively reported in many other studies. ${ }^{1,6,7,10,20-25}$ In the literature, the predominance of males referred to low vision clinics has been explained by the higher risk of visual impairment in males and higher mortality rate in females, ${ }^{6}$ gender-based discrimination in access to eye care clinic, ${ }^{7}$ literacy, and social constraints. ${ }^{24}$ In our study, socio-cultural

Table 2 Frequency distribution of causes of visual impairment by age

\begin{tabular}{|c|c|c|c|c|c|c|c|c|c|c|c|c|c|c|c|c|c|}
\hline \multirow[b]{2}{*}{ 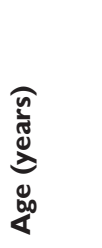 } & \multicolumn{17}{|c|}{ Causes of visual impairment } \\
\hline & $\frac{\varepsilon}{\frac{E}{5}}$ & 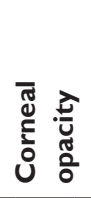 & 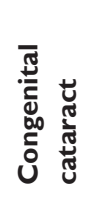 & 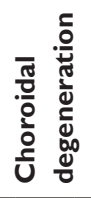 & 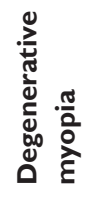 & 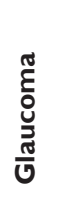 & 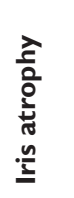 & $\underline{\underline{\Sigma}}$ & 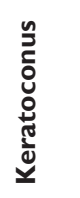 & 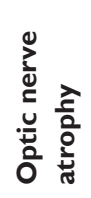 & $\sum_{0}^{0}$ & 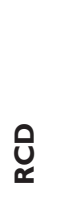 & 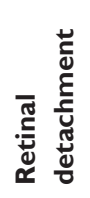 & ò & 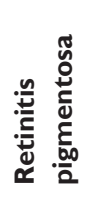 & 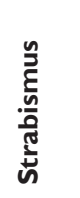 & $\begin{array}{l}\frac{n}{d} \\
\frac{E}{4} \\
0\end{array}$ \\
\hline $0-16$ & 21 & 0 & 5 & 0 & 2 & 2 & I & 3 & 0 & I & 0 & 4 & I & 3 & 8 & I & 1 \\
\hline $17-33$ & 15 & I & I & I & I & 3 & 0 & 6 & 6 & 1 & 1 & 4 & I & 0 & 10 & I & 3 \\
\hline $34-50$ & 3 & 2 & I & 0 & I & I & 0 & 2 & 0 & 0 & 0 & I & 0 & 0 & 3 & I & 0 \\
\hline$>50$ & 4 & 0 & 0 & 0 & 0 & 0 & 0 & 3 & 0 & 0 & 0 & I & 0 & 0 & 4 & 0 & 0 \\
\hline $\begin{array}{l}\text { Total } \\
\text { no (\%) }\end{array}$ & $\begin{array}{l}43 \\
(31.9)\end{array}$ & $\begin{array}{l}3 \\
(2.2)\end{array}$ & $\begin{array}{l}7 \\
(5.2)\end{array}$ & $\begin{array}{l}\text { I } \\
(0.7)\end{array}$ & $\begin{array}{l}4 \\
(3)\end{array}$ & $\begin{array}{l}6 \\
(4.4)\end{array}$ & $\begin{array}{l}\text { I } \\
(0.7)\end{array}$ & $\begin{array}{l}14 \\
(10.4)\end{array}$ & $\begin{array}{l}6 \\
(4.4)\end{array}$ & $\begin{array}{l}2 \\
(1.5)\end{array}$ & $\begin{array}{l}\text { I } \\
(0.7)\end{array}$ & $\begin{array}{l}10 \\
(7.4)\end{array}$ & $\begin{array}{l}2 \\
(1.5)\end{array}$ & $\begin{array}{l}3 \\
(2.2)\end{array}$ & $\begin{array}{l}25 \\
(18.5)\end{array}$ & $\begin{array}{l}3 \\
(2.2)\end{array}$ & $\begin{array}{l}4 \\
(3)\end{array}$ \\
\hline
\end{tabular}

Note: "Others" include Stargardt disease and Wolfram syndrome.

Abbreviations: JMD, juvenile macular degeneration; PVD, posterior vitreous detachment; RCD, rod-cone dystrophy; ROP, retinopathy of prematurity. 
Table 3 LVAs prescribed for distance and near

\begin{tabular}{ll}
\hline & Total no (\%) \\
\hline LVAs for distance & \\
Telescopes & $22(16.3)$ \\
None & $113(83.7)$ \\
LVAs for near & \\
Spectacle-type LVAs (up to +20 D) & $34(25.2)$ \\
Handheld magnifier & $7(5.2)$ \\
Stand magnifier & $\mathrm{I}(0.7)$ \\
Dome lenses & $\mathrm{I}(0.7)$ \\
None & $92(68.1)$ \\
\hline
\end{tabular}

Abbreviation: LVAs, low vision aids.

beliefs were substantial too, and Middle Eastern families tend to prioritize eye care for males over females because the former are required to bear more financial commitment and this may explain the higher number of males seeking low vision services.

The majority of the patients ( $80 \%$ ) of the study population were below 33 years. This result is in accordance with many studies in the developing countries where there is a predominance of younger age group attending low vision clinics. ${ }^{22,24,26,27}$ Noticeably, there was low presentation of younger children in the study with the youngest age reported as 5 years. This is because the targeted clinic receives only children of school age ( 5 years and above), which suggests a limitation of low vision services in Jordan.

The lower frequency of older people who receive low vision services suggests that older people in Jordan may have reduced access to available low vision rehabilitation services due to poor referral from their general practitioners or eye care doctors. Inaccessibility to low vision services due to lack of transportation is also another suggested barrier to low vision service among the elderly. Another explanation for the infrequent appearance of elderly patients into the low vision clinic is the lack of awareness of low vision rehabilitation services where many elderly believe that disease is "God's will" and low vision appliances are not helpful.

Of interest, the study showed that more than half of the patients $(56.3 \%)$ presented with family history of ocular disease. This may suggest genetic predisposition in the occurrence of ocular diseases and vision loss among patients with visual impairment. It has been documented that many ocular diseases that cause visual impairment such as glaucoma, albinism, and RP may be inherited in families, and increased rates of consanguineous marriage may increase the probability of these diseases occurring within families. ${ }^{12,28,29}$

The most common causes of visual impairment in the study population were albinism and RP. This finding is different from other reports in China (congenital cataract and degenerative myopia), ${ }^{22}$ Ghana (corneal and lens pathology), Iran (retinal and choroidal disease), ${ }^{10} \mathrm{Nepal}$ (RP and macular disease), ${ }^{24}$ and Saudi Arabia (optic nerve atrophy). ${ }^{28}$ In developed countries such as the United States and countries in Central and Eastern Europe, cataract and AMD were reported as the leading causes of visual impairment and blindness. ${ }^{29,30}$ Such variations in causes of visual impairment may vary based on geographical area, race/ethnicity, and/or age of patients with visual impairment.

While diabetic retinopathy is considered one of the major causes of visual impairment among patients above 50 years worldwide, ${ }^{4,10,31}$ our study showed that diabetic retinopathy counts for few cases of visual impairment referred to the clinic. However, the findings of the current study contradict with local reports on the high prevalence of diabetes and diabetic retinopathy in Jordan. ${ }^{32-34}$ The low presentation of patients with diabetic retinopathy to the low vision clinic may be explained by the low number of older patients in the study group (8.9\%) in general, and patients who have diabetes, in particular. That may suggest poor referral and poor access of patients with diabetes to the low vision services. Hence, level of awareness of low vision rehabilitation services among patients with diabetes should be questioned and further studied.

The current study showed that there is both low level of prescribing of low vision aids and limited choices of available devices. The only prescribed low vision aids for distance were telescopes. While for near vision, spectacle-type low vision aids were the most commonly prescribed low vision aids followed by hand magnifiers, stand magnifiers, and dome lenses. None of the patients were presented to any electronic devices such as closed-circuit television (CCTV) and tablets.

In Jordan, low vision services are lacking, since most governmental hospitals and ophthalmology department do not have specialized low vision clinics. Low vision aids are also considered expensive appliances that are not covered with any type of insurance as they are considered as a cosmetic or luxurious choice of treatment.

Standard low vision services are only provided in two main places in Jordan: the first is in the Vision Training Centre that is affiliated to the German-Jordanian University (GJU) and based in Amman. The second is the primary eye care clinic that is affiliated to JUST and located in Irbid, where our study was conducted. Neither of these centers are funded by the Ministry of Health in Jordan, and they manage their funds and expenses mostly by donations and charities, especially as low vision aids are usually subsidized or given free to patients to borrow for a short period of time. 
Such a shortage of low vision centers in the country may suggest that the actual number of visually impaired patients who are suitable for low vision aids is underestimated. This should encourage the implementation of new strategies by health care policy makers in Jordan to establish low vision clinics at the major hospitals across the country or even providing mobile low vision clinics to reach all provinces and remote areas in Jordan. Low vision services also need to be more accessible and affordable for patients through coverage of national health insurance or even private insurance.

Additionally, standard low vision clinics should expand their services to cover many aspects of the patient's life; those include physical and psychological needs. This could be possible through employment of a team of trained optometrists, occupational therapists, and psychological rehabilitators in any low vision clinic setting.

Finally, increasing the level of awareness of causes of visual impairment and possible vision rehabilitation services among people is considered a vital strategy for early intervention and in prevention of visual impairment caused by different diseases. This strategy may ultimately improve the quality of life of affected patients.

\section{Conclusion}

To date, this is the first report on causes of visual impairment based on data from a low vision clinic in northern Jordan.

The study suggests reforming guidelines of practice for low vision clinics in Jordan, as low vision services should be presented as an integral part at all primary eye care clinics, and patients' referral to low vision clinics should be emphasized. Furthermore, the national insurance system should include low vision aids as a treatment option for the affected patients. Finally, there is an immense need to implement strategies at primary eye care centers to increase awareness of vision rehabilitation services among patients with visual impairment.

Further information on levels and causes of visual impairment may help the governmental health organizations, along with the private sector, to prioritize resources and develop good strategies to serve that part of the community and enhance the value of rehabilitation among people who are affected. Such information may also facilitate and give attention to screening programs in primary schools and primary health care centers in Jordan. This also may be reflected in the expansion of low vision rehabilitation services in Jordan.

\section{Acknowledgments}

This project was supported by the Deanship of Research at Jordan University of Science and Technology. We would like to thank Dr Ahmad El-Sharif, PhD, from the English Department at Al al-Bayt University (AABU) for proofreading the manuscript.

\section{Author contributions}

Study idea, design and planning (MMB); data collection (EAA and MAB); data analysis and interpretation of the results (MMB and MFH); writing manuscript and reviewing the manuscript (MMB, EAA and MFH). All authors contributed toward data analysis, drafting and revising the paper and agree to be accountable for all aspects of the work. All authors have read and approved the final manuscript of this study.

\section{Disclosure}

The authors report no conflicts of interest in this work.

\section{References}

1. Haddad MA, Lobato FJ, Sampaio MW, Kara-José N. Pediatric and adolescent population with visual impairment: study of 385 cases. Clinics (Sao Paulo). 2006;61(3):239-246.

2. Swenor BK, Muñoz B, West SK. Does visual impairment affect mobility over time? The Salisbury Eye Evaluation Study. Invest Ophthalmol Vis Sci. 2013;54(12):7683-7690.

3. Swenor BK, Muñoz B, West SK. A longitudinal study of the association between visual impairment and mobility performance in older adults: the Salisbury Eye Evaluation Study. Am J Epidemiol. 2014; 179(3):313-322.

4. World Health Organization. Visual impairment and blindness [database on the Internet]. WHO media centre. Available from: http://www.who. int/mediacentre/factsheets/fs282/en/. 2013. Accessed October 1, 2017.

5. Stevens GA, White RA, Flaxman SR, et al. Global prevalence of vision impairment and blindness: magnitude and temporal trends, 1990-2010. Ophthalmology. 2013;120(12):2377-2384.

6. Gao G, Yu M, Dai J, et al. Demographic and clinical characteristics of a paediatric low vision population in a low vision clinic in China. Clin Exp Optom. 2016;99(3):274-279.

7. Uprety S, Khanal S, Morjaria P, Puri LR. Profile of paediatric low vision population: a retrospective study from Nepal. Clin Exp Optom. 2016;99(1):61-65.

8. Kemmanu V, Hegde K, Giliyar SK, Shetty BK, Kumaramanickavel G, McCarty CA. Prevalence of childhood blindness and ocular morbidity in a rural pediatric population in Southern India: The Pavagada Pediatric Eye Disease Study-1. Ophthalmic Epidemiol. 2016;23(3):185-192.

9. Al-Bdour MD, Al-Till MI, Abu-Khader IB. Causes of blindness among adult Jordanians: a hospital-based study. Eur J Ophthalmol. 2002;12(1):5-10.

10. Ramezani A, Pardis M, Rafati N, et al. Causes of visual impairment among patients referred to a visual rehabilitation clinic in Iran. Korean J Ophthalmol. 2012;26(2):80-83.

11. Singh N, Eeda SS, Gudapati BK, et al. Prevalence and causes of blindness and visual impairment and their associated risk factors, in three tribal areas of Andhra Pradesh, India. PLoS One. 2014;9(7):e100644.

12. Tabbara KF. Blindness in the eastern Mediterranean countries. $\mathrm{Br} J$ Ophthalmol. 2001;85(7):771-775.

13. Tang $Y$, Wang $X$, Wang J, et al. Prevalence and causes of visual impairment in a Chinese adult population: the Taizhou Eye Study. Ophthalmology. 2015;122(7):1480-1488.

14. Onyango-Ogony PJ. Preventable causes of blindness. East Afr Med J. 2006;83(4):61-62.

15. Markowitz SN. Principles of modern low vision rehabilitation. Can J Ophthalmol. 2006;41(3):289-312. 
16. Moshtael H, Aslam T, Underwood I, Dhillon B. High tech aids low vision: a review of image processing for the visually impaired. Transl Vis Sci Technol. 2015;4(4):6.

17. Wolffsohn JS, Peterson RC. A review of current knowledge on Electronic Vision Enhancement Systems for the visually impaired. Ophthalmic Physiol Opt. 2003;23(1):35-42.

18. Ramadan W, Asfour W. Prevalence of visual deficits among young men in Jordan. Saudi Med J. 2005;26(12):1968-1970.

19. World Health Organization. ICD Update and Revision Platform: Change the Definition of Blindness, 2010. Available from: http://www. who.int/classifications/icd/ICDRevisionProjectPlan_March2010.pdf. Accessed March 28, 2018.

20. Bagchi K, Bhattacharya S. The profile of visual loss in children - a retrospective study in a referral hospital in India. J Indian Med Assoc. 2006;104(7):366, 368, 370.

21. Bamashmus MA, Al-Akily SA. Profile of childhood blindness and low vision in Yemen: a hospital-based study. East Mediterr Health J. 2010;16(4):425-428.

22. Gao G, Ouyang C, Dai J, et al. Baseline traits of patients presenting at a low vision clinic in Shanghai, China. BMC Ophthalmol. 2015;15:16.

23. Kalloniatis M, Johnston AW. Visual characteristics of low vision children. Optom Vis Sci. 1990;67(1):38-48.

24. Labh RK, Adhikari PR, Karki P, Singh SK, Sitoula RP. Characteristic of low vision patients attending an eye hospital in eastern region of Nepal. Nepal J Ophthalmol. 2015;7(1):33-38.

25. Ntim-Amponsah CT, Amoaku WM. Causes of childhood visual impairment and unmet low-vision care in blind school students in Ghana Int Ophthalmol. 2008;28(5):317-323.
26. Khan SA. A retrospective study of low-vision cases in an Indian tertiary eye-care hospital. Indian J Ophthalmol. 2000;48(3):201-207.

27. Kim JH, Joo KS, Moon NJ. Characteristics of 681 low vision patients in Korea. J Korean Med Sci. 2010;25(8):1217-1221.

28. Alotaibi A. A retrospective study of causes of low vision in Saudi Arabia, a case of Eye World Medical Complex in Riyadh. Global $J$ Health Sci. 2015;8(5):305-310.

29. Khairallah M, Kahloun R, Flaxman SR, et al. Prevalence and causes of vision loss in North Africa and the Middle East: 1990-2010. Br J Ophthalmol. 2014;98(5):605-611.

30. Bourne RR, Jonas JB, Flaxman SR, et al. Prevalence and causes of vision loss in high-income countries and in Eastern and Central Europe: 1990-2010. Br J Ophthalmol. 2014;98(5):629-638.

31. Pelletier AL, Rojas-Roldan L, Coffin J. Vision loss in older adults. Am Fam Physician. 2016;94(3):219-226.

32. Al-Till MI, Al-Bdour MD, Ajlouni KM. Prevalence of blindness and visual impairment among Jordanian diabetics. Eur J Ophthalmol. 2005; 15(1):62-68.

33. Al-Bdour MD, Al-Till MI, Abu Samra KM. Risk factors for diabetic retinopathy among Jordanian diabetics. Middle East Afr J Ophthalmol. 2008;15(2):77-80.

34. Ajlouni K, Khader YS, Batieha A, Ajlouni H, El-Khateeb M. An increase in prevalence of diabetes mellitus in Jordan over 10 years. J Diabetes Complications. 2008;22(5):317-324.
Clinical Ophthalmology

\section{Publish your work in this journal}

Clinical Ophthalmology is an international, peer-reviewed journal covering all subspecialties within ophthalmology. Key topics include: Optometry; Visual science; Pharmacology and drug therapy in eye diseases; Basic Sciences; Primary and Secondary eye care; Patien Safety and Quality of Care Improvements. This journal is indexed on

Submit your manuscript here: http://www.dovepress.com/clinical-ophthalmology-journal

\section{Dovepress}

PubMed Central and CAS, and is the official journal of The Society of Clinical Ophthalmology (SCO). The manuscript management system is completely online and includes a very quick and fair peer-review system, which is all easy to use. Visit http://www.dovepress.com/ testimonials.php to read real quotes from published authors. 